\title{
Revalorización cultural selk'nam: visiones desde la producción de obras artístico-culturales basadas en la etnia ${ }^{1}$
}

Selk'nam cultural reappraisal: views from the production of cultural artistic works based on ethnicity

\section{Carlos Lizana}

Universidad de Santiago de Chile, Santiago, Chile carloslizanaAuchile.cl https://orcid.org/0000-0003-3985-8824

\section{Paula Altamirano}

Universidad de Santiago de Chile, Santiago, Chile paula.altamiranodusach.cl

Universidad de Santiago de Chile https://orcid.org/0000-0001-8563-5264

\section{Resumen}

Este artículo analiza la revalorización cultural del pueblo selk'nam - la cual se da paralelamente a la emergencia social levantada por descendientes selk'nam-, manifestada en obras artístico-culturales inspiradas en la etnia, a través de la visión de las v los creadores culturales. Sus relatos confluven con la contingencia social y cultural de la sociedad chilena, dando origen a ejes centrales en la discusión: esteticidad, consumo y colonialismo. Mediante un enfoque cualitativo, indagamos en las dinámicas e intenciones detrás de las obras analizadas. Las y los entrevistados, concientizadas/os sobre el escenario social, ubican su labor como una herramienta de visibilización y, potencialmente, de descolonización. Sin embargo, del mismo modo, el trabajo vislumbra que estas obras se desarrollan, positiva o negativamente, bajo una lógica de mercantilización cultural de la identidad, basada en las atractivas formas visuales de la etnia selk'nam.

Palabras clave: Selk'nam, revalorización cultural, productores y creadores culturales, etnogénesis, poscolonialismo.

\section{Abstract}

This article analyzes the cultural reassessment of the Selk'nam folk embedded in artistic and cultural works inspired by these indigenous people through the perspective of their cultural producers. Such appraisal happens simultaneously to the process of social awareness raised by Selk'nam descendants. Cultural producers' discourses about their works blend with the current affairs in Chilean society, fueling key dimensions in the cultural debate: aesthetic, consumerism, and colonialism. Under a qualitative frame, we explore the dynamics and assumptions behind the artworks reviewed. Wellinformed about the current social environment, the key interviewees consider their labor as a tool to visibility and, eventually, to decolonizing. Nonetheless, at the same time, the study also highlights that these artworks unfold, for good or bad, under a frame of cultural commodification of identities based upon appealing visual forms of the Selk'nam people.

Keywords: Selk'nam, cultural reassessment, cultural producers, ethnogenesis, postcolonialism. 


\section{Introducción}

Este artículo se sitúa en el actual proceso de etnogénesis del pueblo selk'nam, es decir, en el contexto de su emergencia social en la actualidad (Bartolomé, 2008)², lo cual se refleja en la revalorización cultural que existe a juzgar por representaciones artístico-culturales que contienen elementos identitarios del pueblo, como los cuerpos pintados en la ceremonia del Hain.

Este pueblo se compone de una etnia cuyo territorio, durante siglos, se ubicaba en la Isla Grande de Tierra del Fuego al extremo sur de Chile y Argentina, hasta 1880, cuando, a raíz de la industria ovejera, comienza un proceso de colonización. En 20 años, el pueblo, su gente y su cultura casi fue extinta, debido a la pugna constante entre los nativos y los estancieros colonos. Pese a esto hechos, la figura de los espíritus selk'nam, sus formas y pinturas están, actualmente, en el imaginario colectivo (Harambour, 2018).

A su vez, la ceremonia del Hain consistía en un rito en el que se iniciaba a los jóvenes a la edad adulta y, al mismo tiempo, legitimaba la dominación patriarcal. Esta ceremonia fue registrada fotográficamente por el sacerdote y etnólogo alemán Martín Gusinde, quien fue testigo de una de los últimos Hain en 1936. En 1964, la antropóloga franco-estadounidense, Anne Chapman, realizó un trabajo etnográfico, donde convivió con personas selk'nam y fue parte de las últimas instancias del pueblo (Alonso, 2014).

Al analizar la "imagen selk'nam”, esta se muestra no sólo como un reflejo histórico sino también como una simbología viva en múltiples instancias artísticas, culturales y educativas, que resiste tras el genocidio ejercido sobre el pueblo ${ }^{3}$. Además, debido a que la revalorización cultural traería asociada un cambio a nivel subjetivo en torno a la definición identitaria de las etnias (Boccara, 1999), aparecen y participan de este proceso personas no descendientes ni vinculadas territorial o sanguíneamente con el pueblo (Harambour, 2018), formando un diálogo entre quienes generan las creaciones inspiradas en la etnia, el público demandante y las plataformas de expresión.
A su vez, este resurgimiento estaría vinculado, para bien o para mal, con la mercantilización de la identidad selk'nam. Pues, tal como ha pasado con otros pueblos indígenas, la revalorización, dentro de un contexto neoliberal y de globalización, podría asociarse a la experiencia que entrega lo exótico, diferente o lejano, transformando la etnicidad en mercancía (Comaroff, Jean \& John, 2012).

Este estudio analiza fenómenos relativamente desconocidos en cuanto a lo selk'nam, centrándose, a través de una metodología cualitativa, en personas que trabajan en el área artístico-cultural, específicamente en obras inspiradas en este pueblo. Aportando con material histórico y transformándolo en algo atingente y de interés social, se busca despertar un espíritu analítico y comunicador a través de la selección y revisión de obras que desarrollan temáticas de y sobre la etnia.

Con el fin de generar una fusión entre la visión experiencial y la base teórica, proponemos una problematización en función de la revalorización cultural selk'nam, su reinterpretación en forma de bienes culturales y su caracterización en torno al poscolonialismo y el consumo, en el rango de los últimos cinco años. El objetivo del artículo es identificar y describir las características sociales y culturales observadas frente a la revalorización cultural, mediante la visión de exponentes de bienes artístico-culturales asociados a lo selk'nam. Finalmente, buscamos reconocer y discutir si tales representaciones en torno a la visibilización, exhibición y/o comercialización, cabrían en una condición de admiración y reivindicación del pueblo y/o en las dinámicas de la mercantilización de la identidad cultural selk'nam.

\section{Marco teórico}

\subsection{Revalorización cultural del pueblo selk'nam en Chile}

En el último tiempo, diversas áreas y prácticas han revelado progresivamente la presencia temática selk'nam, graficada en iniciativas territoriales, artístico-culturales y legislativas. Un ejemplo de esto último es el proyecto que busca incorpo- 
rar a la Ley Indígena el reconocimiento del pueblo selk'nam ante el Estado, el cual, al cierre de la edición de este artículo, espera su votación en el Senado. En Chile, hay, al menos, cerca de 1.500 personas que se definen como integrantes de la etnia y están agrupadas en la Corporación Selk'nam Chile (El Desconcierto, 2020).

Bajo este contexto, el concepto de etnogénesis abordaría el presente de la etnia, pues da

cuenta del proceso histórico de la configuración de colectividades étnicas como resultado de migraciones, invasiones, conquistas, fisiones y fusiones, pero de manera más reciente [...] para analizar los recurrentes procesos de emergencia social y política [...] de grupos étnicos que se consideraban extintos, totalmente mestizados o definitivamente aculturados y que de pronto reaparecen en la escena social demandando su reconocimiento (Bartolomé, 2008, p. 107)

En este sentido, la Corporación Selk'nam Chile formaría parte de este proceso, pues su auge responde a demandas sociales e identitarias en torno a su reivindicación como pueblo vivo ante el Estado chileno. La agrupación nace en la Comunidad Covadonga Ona, un grupo de ocho familias, de distintos puntos de Chile, que se reconocieron como descendientes luego de compartir experiencias, recuerdos y costumbres en común: parecido físico, abuelos o bisabuelos adoptados, tradiciones culturales como sentarse en el suelo, usar hierbas para sanar, celebrar el paso a la adultez, no generar vínculos con el cuerpo de un familiar muerto ni nombrarlo, la fascinación por el mar, los mismos cantos y la similitud de técnicas compartidas para fabricar muñecas de junquillo ( $L a$ Tercera, 2018). Actualmente, esta organización se desenvuelve a través de lo que Bartolomé (2008) señala como transconfiguración cultural: estrategias adaptativas a través de las cuales las sociedades subordinadas pasan para sobrevivir a la cultura hegemónica y, para ello, deben reestructurarse frente a los factores externos a los que fueron expuestos.

Herma'ny Molina (2020), Presidenta de la Corporación Selk'nam Chile, señala: "Para la tendencia purista, sumada al silencio de aquellos que sobrevivieron y callaron por miedo y todo el resto lejos del territorio, simplemente desaparecimos". Sin embargo, también evidencia la trascendencia del pueblo: "Se negó a todos los mestizos selk'nam que vivían y eran hablantes de la cultura".

A su vez, la reaparición selk'nam en bienes artístico-culturales permite caracterizar un nuevo escenario donde dialogan quienes generan creaciones inspiradas en la etnia, el público demandante y las plataformas de expresión. Igualmente, el proceso vislumbra nuevas definiciones identitarias a través del vínculo con personas no indígenas o ajenas a la etnia. Estas definiciones estarían en disputa, cuestionadas por Molina:

Hay quienes creen que nosotros por ser selk'nam, tenemos que aparecer con el mismo estereotipo de las fotos, pero tienen que entender que aquí hay un proceso lento y doloroso... nosotros tenemos que encontrar nuestras propias formas de reivindicar prácticas culturales (Molina, 2020).

\subsection{Poscolonialismo: mirada inherente al conflicto indígena}

La colonización que se vivió en América Latina durante el siglo XV persiste en el presente, pues ésta, aparte de producir una verdad absoluta del otro (Said, 2003), proporciona la dominación cultural sobre lo indígena. Es decir, según Spivak (2010), consiste en la adopción de una serie de elementos y comportamientos que componen a las sociedades colonizadas y a la modernidad colonizante y que se tradujeron en la pérdida indígena de la lengua, los valores, las ideas y la cosmovisión.

Además, debido a que el centro de la razón válida se encontraría en Europa, el indígena sería un informante nativo subalterno a quien se le niega la facultad de inteligencia como sujeto político (Spivak, 2010). Bajo esta perspectiva, se daría un uso colonialista en la representación selk'nam debido a la toma de elementos propios de su cosmovisión bajo una nueva reinterpretación

La colonialidad también produjo un sistema de industria medial en dos áreas: la educación y la cultura ligada al espectáculo, las cuales operan como una dominación simbólica sobre los sub- 
alternos indígenas en base a la objetificación, es decir, la creación de una necesidad de abastecimiento en torno a productos, creando una identificación simbólica (Spivak, 2010). La representación selk'nam en obras artístico-culturales se verificaría a través de la materialización de algunos aspectos identitarios de la etnia en un uso otorgado por el imaginario colectivo (Harambour, 2018), es decir, el del público. En este contexto, la revalorización cultural que se da sobre el pueblo puede interpretarse a través de tal dominación simbólica.

Asimismo, el colonialismo interno ha producido jerarquías, estatus y diferenciación racial, étnica, sexual y de género entre personas, administradas por organismos estatales y privados, estableciendo parámetros comunes que han sido naturalizados y sistematizados: "Las élites adoptan una estrategia de travestismo y articulan nuevos esquemas de cooptación y neutralización. Se reproduce, así, una 'inclusión condicionada'" (Rivera Cusicanqui, 2010, p. 60). De esta forma, el escenario selk'nam actual podría estar condicionado bajo ciertos elementos estandarizados por la sociedad.

Sin embargo, el marco reciente propiciaría, también, una visibilización y empoderamiento de lo ch'ixi'; o, en palabras de Rivera Cusicanqui (2010), la coexistencia en paralelo de múltiples diferencias culturales, las cuales se reproducen a sí mismas desde el pasado, relacionándose, entre ellas, de forma contenciosa. Por tanto, en la modernidad, "lo indígena florece desde el presente, en un movimiento continuo que se retroalimenta constantemente del pasado sobre el futuro y que vislumbra una esperanza de descolonización" (Rivera Cusicanqui, 2010, p. 55).

En este sentido, la utilización de la imagen selk'nam posibilitaría la opción de una visión crítica del pasado y presente, favoreciendo una narrativa reflexiva "capaz de desenmascarar las distintas formas del colonialismo contemporáneo" , ya que "el registro visual nos permite descubrir los modos en que el colonialismo se combate, se subvierte, se ironiza" (Rivera Cusicanqui, 2010, p. 5-6). Esto se ve reflejado en las calles, donde la revalorización de elementos identitarios de la etnia permitiría el posicionamiento de rasgos descolonizantes a partir de la sociabilización de contenidos y la puesta en escena de características culturales del pueblo, lo que favorecería la democratización cultural.

El vínculo de lo indígena en la modernidad puede abordarse desde un enfoque descolonizador de parte de quienes crean arte y cultura a partir de su imagen. Una revisión crítica de la historia en torno a sucesos que se dieron como únicos (Nora, 2010), podría ser el sustento de las personas externas no indígenas al representarlos. A su vez, aportar a deconstruir la imagen de dominación hegemónica impuesta a partir de la colonización de pueblos (Said, 2003) responde a la motivación de dotar de nuevas perspectivas a los hechos relacionados con el pasado selk'nam.

De esta forma, el poscolonialismo podría abrir dos caminos simultáneos dentro de la actualidad: la imagen selk'nam como un ejemplo del concepto de dominación cultural (Spivak, 2010) o la representación de la etnia como una herramienta de visibilización y reflexión a lo indígena en el presente (Rivera Cusicanqui, 2010). Esta dualidad es necesaria de considerar, teniendo en cuenta las características del escenario artístico-cultural en donde se representan las obras con temática selk'nam en Chile.

\subsection{Consumo y distinción social de las obras inspiradas en el pueblo selk'nam}

El análisis sobre la creación de obras artísticaculturales selk'nam como producto de la revalorización cultural del pueblo rescata dos visiones dicotómicas destacables desde algunas teorías tradicionales. Primero, el análisis de Adorno y Horkheimer, quienes se refieren a la reproducción de bienes estandarizados que son consumidos y aceptados sin oposición por el público, como eslabón de un círculo de manipulación y dominio de los individuos (Adorno \& Horkheimer, 1944). De aquello, se desprende una visión profunda sobre "la pérdida" de lo que vuelve única a una obra al ser reproducida en serie, como, por ejemplo, cuando hay un uso de la imagen selk'nam con el propósito que se prefiera, sin cuestionar la opinión de las y los integrantes del pueblo en cuanto a la utilización de ésta. 
Por otro lado, el concepto de liberalismo cultural contempla una libre circulación de productos culturales para la sociedad y su acceso a ellos (Busquet, 2008). Sobre las obras inspiradas en "lo selk'nam", considerando esta visión, existe la posibilidad de hablar de una democratización de su imagen a partir de su sociabilización, lo que se traduciría en una ventana al conocimiento sobre la etnia, su historia y su legado relevando su aporte cultural. Desde allí resulta interesante la postura de Walter Benjamin y complejizarla con lo que señala Busquet (2008): la reproductibilidad técnica de una obra sería el paso en que ésta se desapega de lo que la hace única, pasando a ser parte de quien la desee interpretar (Benjamin, 2003). Por lo tanto, en ese proceso, se produce una suerte de liberación del arte y la cultura. En este sentido, para que la cultura obtenga una lógica democratizadora y no meramente mercantil, las políticas culturales estatales deben intervenir activamente (Benjamin, 2003), desafío pendiente para el escenario chileno, puesto que gran parte del financiamiento de las obras artístico-culturales, luego del retorno a la democracia, se da a través de fondos concursables, de forma descentrada y poco constante (Garretón, 2008).

Ahora bien, desde una visión contemporánea, frente a la problematización de la y el indígena en la sociedad moderna -y su relación con el mercado-, es posible identificar fenómenos de marketing indígenas que generan, según la pareja Comaroff, un potencial afectivo, material y expresivo que produce una transformación de la etnicidad en mercancía, vendiéndose como una experiencia, un valor relacionado a lo lejano, lo diferente y lo exótico (Comaroff \& Comaroff, 2012). La imagen selk'nam se podría hallar en un mercado simbólico, que posee un nicho laboral y una difusión intencional o no- de la cultura selk'nam: es en este mercado donde lo distintivo se vuelve mercantilizable al ser atractivo para personas ajenas al pueblo.

Entonces, existen “géneros de apariencia cada vez más novedosos, con cifras de negocios siempre crecientes, lo que le asigna una posición y una función estructural cada vez más fundamental a la innovación y experiencia estética" (Brunner, 1998, p. 66). Tal es el caso de los bienes inspirados en el pueblo selk'nam que resultan atractivos por su apariencia llamativa y exótica.
¿Qué es lo llamativo en lo selk'nam? La respuesta podría radicar en sus cuerpos pintados. Ese vínculo entre lo ceremonial y lo estético se despega completamente de la realidad actual chilena y despertaría interés en las personas por ser algo desconocido, sin un argumento más que el atractivo visual y la curiosidad que genera. De allí, luego, las y los más interesados profundizarían en el pueblo, su historia o cultura.

Por tanto, las obras basadas en la imagen selk'nam contienen un aporte visual distintivo, que puede generar un consumo desmarcado del propio contenido, pues "cuando el primer vistazo es el del amante de lo exótico, es decir, de las diferencias pintorescas; aquel que, por decisión o por simple ligereza se apega prioritariamente a las curiosidades superficiales [...] frecuentemente producidas y perpetuadas por la intención de turistas apresurados que ni conocen la lengua" (Bourdieu, 2003, pág. 25); aquel es el reflejo de la atracción que se produce hacia un elemento diferente, llamativo, solo por el hecho de tener una distinción, sin previo entendimiento del trasfondo existente o existido de este.

Bajo esta perspectiva, es posible identificar un intento por reconvertir un patrimonio para reinsertarlo en nuevas condiciones de mercado y, con ello, generar la posibilidad de adquirir distinción y ascenso social a partir de la obtención del capital cultural que se encuadre en una cultura legítima (Bourdieu, 1988). Entonces, la reaparición del pueblo selk'nam, graficada a través de obras artístico-culturales, podría generar una revaloración de su cultura, o al menos de su imagen, no solo en cuanto a su uso sino también a su resignificacin cultural.

\section{Metodología de la investigación}

A través de una investigación con enfoque cualitativo y una perspectiva comunicacional del fenómeno de la revalorización cultural y su significado, este trabajo se enmarca en la sociología de la cultura. A partir del comportamiento observable de las y los participantes insertos en un mismo contexto (Sampieri, 2010), este caso se enfoca en la relación significante de los diferentes bienes 
culturales con temáticas selk'nam.

El problema en cuestión necesita profundizar fenómenos relativamente desconocidos en cuanto a “lo selk'nam” Por lo tanto, el estudio consideró un diseño exploratorio para indagar relaciones no abordadas o consideradas en trabajos previos. Adicionalmente, recurrimos a un diseño descriptivo al generar un relato sobre las características del escenario artístico-cultural presente.

El proceso investigativo se desarrolló territorialmente según la ubicación del objeto de estudio: las representaciones artístico-culturales que se hayan dado en Santiago de Chile, por lo que se consideró a 19 obras artístico-culturales realizadas y/o exhibidas entre los años 2015 y 2018 en dicha ciudad. Por lo que es pertinente aclarar que la investigación podría presentar sesgos de representatividad. La investigación se enfocó en las y los 23 productores/creadores de estas obras, y su visión sobre la reaparición de la imagen selk'nam y sus creaciones, no así en los consumidores y su caracterización. La decisión de no considerar la circulación y recepción de las obras respondió al alcance del estudio, así como a las posibilidades materiales y de tiempo concretas del equipo, y no a que esa dimensión sea por naturaleza menos interesante. Sin embargo, este trabajo da cuenta de las obras, sus realizadores ya sea individuales o colectivos responsables de la representación de las obras seleccionadas.

Los autores o productores se agrupan en cuatro categorías, según su expresión cultural: "Artes escénicas”, “Artes Visuales y Performance”, “Diseño y Artesanía" y "Fotografía y Audiovisual". Se utiliza esta clasificación para recalcar que las formas de arte, expresión y comunicación pueden problematizar una identidad, usarla, transfor-

Tabla 1: Categorías y obras de representación con temática selk'nam

\begin{tabular}{|c|c|c|c|}
\hline $\mathbf{N}^{\circ}$ & Categoría & $\begin{array}{c}\text { Tipo } \\
\text { de representación }\end{array}$ & Nombre \\
\hline 1 & \multirow{5}{*}{ Artes escénicas } & Obra de danza-teatro & Yikwa ni selk'nam - nosotros somos los selk'nam \\
\hline 2 & & Obra de teatro & A la sombra de los selk'nam \\
\hline 3 & & Obra de teatro lambe lambe & Trilogía Selk'nam \\
\hline 4 & & Obra de teatro & Kamshout, el otoño y el pueblo selk'nam \\
\hline 5 & & Obra de teatro & El fin de los Howenh \\
\hline 6 & \multirow{7}{*}{$\begin{array}{l}\text { Artes Visuales y } \\
\text { Performance }\end{array}$} & Performance & La resurrección de los muertos \\
\hline 7 & & Performance & Proyecto Selk'nam \\
\hline 8 & & Pintura & Historia violenta y luminosa \\
\hline 9 & & Escultura & Aïna: una mirada al mundo Selk'nam \\
\hline 10 & & Taller de grabado & Proyecto Sol en Posada del Corregidor \\
\hline 11 & & Muralismo & Hombres pájaros \\
\hline 12 & & Pintura & Selknam I \\
\hline 13 & \multirow{3}{*}{ Diseño y Artesanía } & Diseño de vestuario & Air Max 1 "Los Primeros" \\
\hline 14 & & Diseño de vestuario & Origen \\
\hline 15 & & Artesanía & Sur Artesanía Latinoamericana \\
\hline 16 & \multirow{4}{*}{ Fotografía y Audiovisual } & Montaje audiovisual & Hain, interpretación de un rito \\
\hline 17 & & Corto animado & Ma'hai selk'nam \\
\hline 18 & & Corto animado & Halahaches \\
\hline 19 & & Exposición fotográfica & Hain, interpretación de un rito \\
\hline
\end{tabular}


marla, discutirla y revivirla. Al mismo tiempo que, puesto que cada obra contiene diversos elementos, ellas podrían aportar fundamentos que problematicen fenómenos como visibilización, educación, mercantilización y/o emergencia u opción laboral.

Para la recolección y análisis de datos se realizaron entrevistas individuales semiestructuradas a las y los productores/creadores a partir de una pauta de 24 preguntas abiertas en base a los ejes teóricos pertinentes. Posterior a esto, se desarrolló un análisis de contenido a sus respuestas, organizando, por categoría, los datos recolectados en una grilla o matriz de análisis. La matriz de análisis cuenta con los ejes centrales descritos en el Marco Teórico y la pauta de preguntas, donde las respuestas resumidas son asignadas según las divisiones: «dominantes/mayoritarias», «marginales/minoritarias» y «otro o novedoso», dando así paso a un análisis comparativo entre las respuestas de las y los entrevistados. Por otro lado, también se participó en la observación de algunas de las obras, sin embargo, este elemento no fue considerado para el análisis, sino para tener más claridad del contexto en el que se desarrollan y entender con más claridad las referencias y respuestas aludidas en las entrevistas.

\section{Visiones de las y los creadores artísticos sobre la revaloración cultural selk'nam}

De acuerdo al trabajo de campo, los primeros vínculos con la etnia se producen durante la educación escolar, al menos de manera superficial en un primer momento. De hecho, los acercamientos más profundos o complejos de los sujetos a la etnia se producen a partir de sus experiencias universitarias o personales. A partir de los testimonios recogidos, las y los creadores comenzaron a familiarizarse y vincularse con la etnia y su producción cultural entre los años 2012 y 2014.

El trabajo del sacerdote y etnólogo alemán, Martín Gusinde, y de la antropóloga franco-estadounidense, Anne Chapman, sobre el pueblo selk'nam es identificado como central por los entrevistados. Éstos reconocen que, en general, han estudiado al pueblo principalmente a través de los textos y registros fotográficos de Gusinde y de Chapman. Además, algunos destacan sus experiencias directas (conversaciones, inmersión) con descendientes selk'nam, encuentros cuyo propósito era tener un mayor acercamiento al pueblo. Una sola de las entrevistadas (Entrevistada V. B.) asegura no haber realizado ninguna investigación previa para familiarizarse con el pueblo, sino que se dio a partir de la creación de la obra misma.

Sobre el trabajo artístico-cultural que han realizado basados en los selk'nam, se distinguen tres grandes ejes de representación: la mitología y estética, la representación de la lengua y el genocidio. El primero es el que más se repite y su componente principal corresponde a los cuerpos pintados vinculados a la ceremonia del Hain.

De este modo, la esteticidad del pueblo les entrega a las obras autenticidad y complejidad a través de sus rituales, su cosmovisión y su capacidad de supervivencia. A su vez, las representaciones poseen un sello de exclusividad determinado por el formato de éstas, tales como los efectos de sonido, los juegos de luces, la puesta en escena, la originalidad e innovación de ideas, y la idea de intentar resignificar su cultura aparece como una contribución.

A partir de las cuatro categorías de análisis, la mayoría de las obras considera en su puesta en escena elementos propios de la ritualidad selk'nam mediante los cuerpos pintados. Es decir, la esteticidad de la etnia es desarrollada mezclando las capacidades materiales y de formato propias de cada una de las categorías.

A partir de esto, la creación de las obras respondería, primero, a la necesidad de visibilizar al pueblo y la permanencia y transmisión de su cultura. En segunda instancia, al ahondar en su cosmovisión, tradición e historia, ya que se asume un desconocimiento por parte del público chileno sobre la temática. No obstante, los actores consultados concuerdan con que esa falta de información que circula sobre el pueblo no perjudica su popularidad, pues creen que esta etnia es más reconocida precisamente debido a sus aspectos distintivos.

De esta forma, en palabras de uno de los entrevistados se vincula la demanda de bienes inspirados en "lo selk'nam" a las ganas de conocer, preservar 
y reconectarse con la cultura de un pueblo único y que hay cierta conciencia por la rigurosidad y respeto al crear una obra y que eso no implica aprovecharse de ella. Mientras que otro de nuestros informantes (Entrevistado E. M.) advierte cierto irrespeto por la ilustración del genocidio como un fetiche para la audiencia.

Las convicciones y, al mismo tiempo, conciencia sobre la visibilización, pero, al mismo tiempo, riesgo de mercantilización se dan en un contexto que los informantes reconocen como colonialismo interno en la sociedad chilena. Dicho colonialismo interno se refleja en la percepción de superioridad frente al indígena, la cual se grafica en actos de discriminación y xenofobia. Ante esto, creadores y creadoras conciben sus obras como armas de combate contra esta lógica. Sin embargo, también se cuestionan la capacidad efectiva de lograr una transformación sobre la base de la visibilización y la reivindicación del pueblo selk'nam en Chile. Sobre todo, porque creadores y creadoras consideran que es altamente probable y factible la comercialización y comercialización de bienes inspirados en el pueblo selk'nam. En este aspecto, hay diversas formas de caracterizar la relación entre obra y comercialización, sobre todo dependiendo del tipo de obra.

Por ejemplo, la comercialización de una obra clasificada en la categoría de "Fotografía y Audiovisual" (producciones audiovisuales y una exposición fotográfical es factible y posible si la obra representa una resignificación. En el caso de las obras correspondientes a "Diseño y Artesanía” Ivestuario y artesanado), la comercialización opera como vehículo a través del cual se difunde la cultura del pueblo. En el caso de las y los autores de performance, pinturas, esculturas y grabados ("Artes Visuales y Performance"), advierten que, con la comercialización, sólo quedaría lo superficial de la obra, perdiendo su esencia. Finalmente, en el caso de los informantes vinculados a obras de teatro y danza ("Artes Escénicas"), concuerdan en que el pueblo selk'nam como pueblo, tema, estética e inspiración es totalmente comercializable y que existe un negocio al respecto.

El campo de productores y creadores culturales de obras inspiradas en el pueblo selk'nam reconocen el vínculo entre obra y comercialización, con un abrumador consenso entre quienes se desempeñan en "Artes Escénicas" y en "Diseño y Artesanía". En el campo de las "Artes Visuales y Performance" hay acuerdo, también, en que debiera retribuirse de alguna manera al pueblo. En el caso de las experiencias y percepciones, destaca el daño provocado a una máscara selk'nam incluida en una exhibición luego de la negativa de los organizadores a vender la pieza pues no se encontraba a la venta.

Así, las y los creadores se posicionan en torno a las articulaciones entre visibilizar y reivindicar al pueblo selk'nam y las tensiones y riesgos de los posibles usos comerciales de las obras. Estas articulaciones y tensiones pueden manifestarse en su ejecución, a través de los diversos formatos de cada categoría y, también, a raíz del vínculo que se genere con la audiencia.

Es importante destacar que "lo selk'nam" genera interés a nivel local, pero también internacional: por ejemplo, algunas entrevistadas (V. B. y C. O.) han recibido encargos para realizar obras basadas en los selk'nam para ser exhibidas y reproducidas en países europeos. Otro informante (Entrevistado I. E.) expuso su obra en un circuito internacional reconocido.

La eventual fetichización de las representaciones artísticas y culturales basadas en los selk'nam es reconocida por los entrevistados, quienes advierten que la globalización y las redes sociales contribuirían a ello. El consumo, entonces, de estos artefactos respondería a una moda y no tanto al conocimiento sobre la etnia por parte de la audiencia. Al decir de una de las entrevistadas (G. R.), tales obras pueden contribuir a adquirir cierto estatus, un valor cultural o una inversión en capital cultural por parte del público.

Por último, los informantes advierten una presencia muy débil o inexistente del Estado en fomentar y promover las culturas de los pueblos originarios y aseguran que no hay iniciativas en torno a "lo selk'nam", al menos masificadas ${ }^{5}$. Las y los exponentes ejemplifican, destacando que el material se crea y difunde a través de financiamiento privado. La entrevistada A. J. advierte que existe un estancamiento creativo debido a las pocas iniciativas basadas en el pueblo. 


\subsection{Acercamientos y diferencias en representaciones culturales selk'nam: discusión entre la teoría y la práctica}

Las y los artistas se vinculan con la revalorización cultural del pueblo selk'nam de diferentes formas: a través de la lectura y la autoeducación, así como también por la vía de vincularse personalmente con descendientes selk'nam. Ello reflejaría, siguiendo a Bartolomé (2008), la disposición de individuos no indígenas sinceramente interesados en (re) conocerlos, validarlos como pueblo vivo y, por lo tanto, como cultura viva, manteniéndose y resistiendo en/a la sociedad chilena.

Las dimensiones del pueblo selk'nam más abordadas por el conjunto de autores acá retratados corresponden a la mitología y estética, la representación de la lengua y el genocidio. Entonces, en el proceso de revalorización cultural de "lo selk'nam", "lo indígena" florece desde el presente (Rivera Cusicanqui, 2010): en el caso acá discutido, gracias a los bienes culturales que consideran entre sus resignificaciones la búsqueda de una visibilización y una reivindicación del pueblo y su cultura.

El arte puede ser un arma de combate ante una lógica colonialista pues contribuiría a identificar y denunciar problemas, promover debates culturales, políticos o sociales, por ejemplo. En tanto herramienta que expone temas o problemas, el arte los revive, transforma o reinventa en un escenario actual. Las materialidades, lenguajes y objetos propios de cada disciplina artística resaltan estos problemas al (re)ponerlos en escena.

No obstante, la capacidad efectiva del arte de generar cambios es, más bien, incierta. Sin embargo, contribuiría a desarrollar perspectivas más críticas frente a actitudes coloniales en la relación con los pueblos originarios. Siguiendo a Said (2003), podemos dotar de nuevas perspectivas los hechos pasados y, por esa vía, colaborar a deconstruir la imagen de dominación hegemónica impuesta a partir de la colonización.

Simultáneamente, la mercantilización de estos asuntos, problemas y sujetos es recurrente y, por lo tanto, las obras adquieren nuevas funciones. De este modo, se generaría una nueva conciencia sobre "lo étnico", descubriendo aquel potencial, definido como aquello que radica en lo afectivo, lo material y expresivo y que produce una transformación de la etnicidad en mercancía, guiado por aquello que es diferente, "lo indígena", lo exótico (Comaroff \& Comaroff, 2012).

Que los selk'nam, sus temas, representaciones, historias y artefactos tengan potencial comercial, también lo globaliza. El interés del público extranjero por las manifestaciones y artefactos culturales selk'nam ilustra este punto. Tanto en Chile como fuera del país, la obra se vende como una experiencia relacionada a lo lejano, lo diferente y lo exótico (la otredad), siguiendo a Jean y John Comaroff (2012) en relación a tribus y pueblos originarios.

Unas obras más "globalizadas" hacen que tengan un mayor alcance y despierten una gran demanda. La idea de liberalismo cultural (Busquet, 2008) se vuelve real cuando existe una libre circulación de obras basadas en este pueblo - u otros - y que están expuestas a la crítica e interpretación de la gente, cuestión confirmada por las y los entrevistados que declararon generar un esfuerzo porque sus obras alcancen a la mayor cantidad de personas, de la forma más accesible posible.

En este escenario, es necesario mencionar que el Estado chileno contribuye escasamente en este campo a pesar del rol fundamental que éste debe cumplir en la promoción y democratización en la cultura (Benjamin, 2003).

A pesar de las "buenas intenciones", las obras basadas en la producción e historia de pueblos originarios, en particular en el caso de los selk'nam, arriesgan caer en una lógica de moda si su aporte se limita solo a lo visual y no a el espesor de sus contenidos y significancia, alimentando la dominación simbólica en los subalternos indígenas (Spivak, 2010). Siguiendo a Bourdieu (2003), un actor o espectador ajeno puede eventualmente generar sólo un acercamiento a la obra, debido a las imágenes pintorescas o al afán de destacar en una cultura legítima y que le permita ascender socialmente. El concepto de colonialidad en este sentido se vuelve crucial para comprender mejor estos procesos. Siguiendo a Said (2003), una occidentalización que, finalmente, se traduce en una apropiación o adaptación cultural con fines, en este caso, meramente estéticos. 
De esta manera, el mercado simbólico en que circula la imagen selk'nam podría estar condicionada por la capacidad de reflexión y el capital cultural que se obtenga a partir de ella. Según Bourdieu (1988), desde la perspectiva del campo social, los sujetos se esfuerzan por alcanzar cierto estatus y reconocimiento social que buscan, entre otras estrategias, a través de cultivar capital cultural por medio de bienes y consumos que encarnen características distintivas. Por la vía de la distinción, entonces, dada por el ascenso, el estatus y reconocimiento en una cultura legítima los sujetos buscan destacarse de su entorno. El acceso y consumo a obras artístico-culturales únicas y especiales forma parte de ese intento de distinción. Este fenómeno es reconocido, también, por los mismos entrevistados (Entrevistada G. R.).

\section{Conclusión}

Este trabajo identificó un vínculo entre la producción artístico-cultural de obras inspiradas o basadas en el pueblo selk'nam y el actual proceso de etnogénesis que se concreta a través de procesos de revalorización cultural que generan los bienes inspirados en este pueblo. Esto conecta, visibiliza y potencia el escenario social y político en curso, levantado por la demanda de descendientes selk'nam de relevar a la etnia como viva y parte orgánica de los pueblos indígenas que componen al mundo.

Al analizar la puesta en valor de ciertas representaciones e identidades culturales, se reconoce el poder del arte. En efecto, los creadores y creadoras artístico-culturales le otorgan a las obras un carácter reivindicador para el pueblo a partir de su visibilización cultural, su legado y su presente. Esto, como estrategia de resistencia a la mirada poscolonialista de la sociedad chilena.

Las obras, en diálogo con sus realizadores, encarnan una voluntad democratizadora en el afán de masificarlas tanto económica como territorialmente. En las experiencias de los informantes clave, el rol del Estado en promover el arte y cultura sobre y del pueblo selk'nam es más bien marginal y el financiamiento y patrocinio de obras en este campo es, principalmente, de carácter privado a través de instancias con apoyo empresarial, de fundaciones y/o de individualidades. No obstante, el neoliberalismo globalizado representa la oportunidad para que la obra pueda ser tomada a partir de sus componentes estéticos, por lo que produce una conciencia y problematización sobre lo distintivo que puede resultar la imagen selk'nam y la facilidad con la que puede transformarse su contenido en moda.

A su vez, existe, entre creadores/as, la noción de que el consumo se da por la obtención de estatus o valor agregado que otorgan los contenidos selk'nam, a través del lazo entre el aporte visual distintivo y su consecuente directo a la ascendencia social que podrían entregar las obras exóticas o diferentes, bajo la lógica de una cultura legítima imperante.

Se analiza que la resignificación de "lo selk'nam", materializado en manifestaciones artístico-culturales, está vinculada, positiva o negativamente, a la mercantilización cultural de la identidad del pueblo. Por tanto, el escenario en el que se presentan las obras, enlazado al poscolonialismo e inmerso dentro de las dinámicas propias del neoliberalismo, responde a la conciencia de las y los exponentes por visibilizar al pueblo, aportando directamente al fenómeno de la revalorización cultural selk'nam presente en Chile.

Finalmente, entonces, este fenómeno se convierte en una forma de expresión resignificativa sobre la cultura selk'nam, fabricada bajo parámetros globales donde impera un modelo económico que trabaja con aquello que estéticamente vende un mensaje, un discurso o una idea. De este modo, en el contexto actual, la relación entre el símbolo selk'nam y la contingencia sugiere una conversación entre la estética y el acto político detrás de la visibilización. Adicionalmente, -aunque las y los entrevistados vislumbraron que no existe certeza de si su trabajo concluye o no en un efecto descolonizador - queda al descubierto que, para eliminar lógicas colonialistas de la población, es necesario conectarla con muestras visuales que posean un potencial estético y un espíritu combativo, otorgado por su creador/a (de allí, el relevante rol de las y los artistas), las cuales reposen en el espacio público como figuras abiertas a la admiración, análisis y cuestionamiento. 


\section{Notas}

1. Este artículo se basa en la tesis de pregrado desarrollada por autores para obtener el título de Periodistas de la Universidad de Santiago de Chile, la cual lleva por nombre: “Lógicas sociales y culturales presentes en la etnogénesis del pueblo selk'nam: La visión de los productores de creaciones culturales", en donde también participó Yocelyn Valdés Muñoz, quien se convirtió en un pilar fundamental para sacar a flote aquella investigación.

2. Etnogénesis se refiere a “los recurrentes procesos de emergencia social y política (...) de grupos étnicos que se consideraban extintos, totalmente mestizados o definitivamente aculturados y que de pronto reaparecen en la escena social demandando su reconocimiento" (Bartolomé, 2008, p. 107). Para este estudio, utiliza el concepto "reaparición y/o revalorización cultural" para abordar una faceta de la etnogénesis donde participan elementos y personas externas a la etnia y que aportan al proceso.

3. Siguiendo a Alonso (2014), el pueblo selk'nam fue víctima de un genocidio que comenzó con los europeos que pisaron piso magallánico en el siglo XVI; desde las expediciones en busca de oro hasta las misiones salesianas que intentaban "civilizarlos". En 1883 se inició oficialmente la colonización de Tierra del Fuego. Los territorios fueron interveni- dos por las grandes estancias ovejeras que intervinieron la flora y fauna del lugar, influyendo en la alimentación de los selk'nam quienes, como parte de sus estrategias de sobrevivencia, robaban ovejas a los estancieros quienes los perseguían y mataban masivamente. José Menéndez, uno de los magnates controladores de la industria ovejera, fue un personaje clave en la matanza (Alonso, 2014). En apenas 20 años, la población selk'man prácticamente desapareció. El Estado chileno no tomó medidas para impedir, detener o sancionar la masacre del pueblo.

4. Ch'ixi: rasgo indígena que tiene todo el mundo y que se traduce a un mestizaje descolonizado y orgulloso de sus raíces (Rivera Cusicanqui, 2010, p. 7).

5. Se hallan iniciativas culturales inspiradas en el pueblo selk'nam en establecimientos de uso público de la ciudad de Santiago, como en la Biblioteca de Santiago con la representación familiar “El fin de los Howenh" (El Mostrador, 2017), el Museo de la Memoria y los Derechos Humanos con la obra acústica "Al final del Mundo... los Selk'nam" (Museo de la Memoria, 2018) y en el Museo Violeta Parra con la pieza teatral "A la sombra de los selk'nam" (Museo Violeta Parra, 2018). A su vez, se aprecia un apoyo constante a aquellas que se desarrollan en la zona del extremo sur de Chile, el cual representa el territorio nativo selk'nam, como por ejemplo en el Museo Martín Gusinde o el Museo de Magallanes.

\section{Referencias}

Adorno, T. \& Horkheimer, M. (1944). Dialéctica de la llustración. Madrid: Editorial Trotta.

Alonso, J. (2014). Menéndez, rey de la Patagonia. Santiago de Chile: Catalonia.

Bartolomé, M. A. (2008). La etnogénesis del Pueblo Mbya-Guaraní. Ciudad de México: ILHA, Revista de Antropología.

Benjamin, W. (2003). La obra de arte en la época de su reproductibilidad técnica. México D.F.: Editorial Itaca.

Boccara, G. (1999). Etnogénesis Mapuche: resistencia y restructuración entre los indígenas del centro-sur de Chile. Santiago: The Hispanic American Historical Review.

Bourdieu, P. (1988). La Distinción. Madrid: Taurus.

Bourdieu, P. (2003). Capital cultural, escuela y espacio social. Buenos Aires: Siglo Veintiuno.

Brunner, J. (1998). Globalización cultural y posmodernidad. Santiago de Chile: Fondo de Cultura Económica.

Busquet, J. (2008). Lo sublime y lo vulgar. La «cultura de masas» o la pervivencia de un mito. Barcelona: Editorial UOC.

Comaroff, J. \& Comaroff, J. (2012). Etnicidad S.A. Madrid: Katz Editores.

El Desconcierto. (24 de junio de 2020). "Cámara de Diputados aprueba proyecto que incluye al pueblo Selk'nam entre las etnias originarias reconocidas por el Estado". https://www. eldesconcierto.cl/2020/06/24/camara-de-diputados-aprobo-inclusion-de-pueblo-selknam-entre-las-etnias-originarias-reconocidas-por-el-estado-de-chile/ 
El Mostrador. (18 de marzo de 2017). Cultura, El Mostrador. Obtenido de Obra de teatro familiar "El fin de los Howenh" en Biblioteca de Santiago: https://www.elmostrador. cl/cultura/2017/03/18/obra-de-teatro-familiar-el-fin-de-los-howenh-en-bibliotecade-santiago/

Garretón, M. A. (2008). Las políticas culturales en los gobiernos democráticos en Chile. En: Bayardo, R. Ed. Políticas culturais na Ibero-América (pp. 75-118). Salvador: EDUFBA.

Harambour, A. (2018). Los prohombres y los extintos. Patrimonio, identidad e historiografía regional en Magallanes. Santiago de Chile: Cuadernos de Historia (online).

La Tercera. (20 de noviembre de 2018). Paula. Obtenido de Ser selknam en el siglo XXI: https:// www.latercera.com/paula/selknam-siglo-xxi/

Molina, H. (14 de julio de 2020). Presentación historia y actualidad selk'nam en Chile. Conversatorio Voces de mujeres Selk nam hoy, a propósito de su reconocimiento como pueblo vivo y justicia histórica. Dirección de Vinculación con el Medio de la Universidad Católica Silva Henríquez (UCSH), Santiago.

Museo de la Memoria. (25 de septiembre de 2018). Exposiciones, Museo de la Memoria y los Derechos Humanos. Obtenido de “Al Final del Mundo..., los Selk'nam” de Andreas Bodenhofer: https://web.museodelamemoria.cl/exposiciones/tierra-del-fuego-alfinal-del-mundo-de-andreas-bodenhofer/

Museo Violeta Parra. (15 de mayo de 2018). Noticias, Museo Violeta Parra. Obtenido de Obra de teatro familiar "A la sombra de los selk'nam" se presentó en el Museo Violeta Parra: https://www.museovioletaparra.cl/reserva-gratis-entrada-la-obra-teatro-familiarla-sombra-los-selknam/

Nora, P. (2010). Les lieux de mémoire. Chicago: University of Chicago Press

Rivera Cusicanqui, S. R. (2010). Ch'ixinakax utxiwa. Una reflexión sobre prácticas y discursos descolonizadores. Buenos Aires: Tinta Limón.

Said, E. (2003). Orientalismo. Madrid: Debolsillo.

Sampieri, R. H. (2010). Metodología de la investigación. México D.F: The McGraw-Hill.

Spivak. G. (2010). Crítica de la razón poscolonial. Hacia una historia del presente evanescente. Madrid: Ediciones Akal.

- Sobre lxs autores:

Carlos Lizana Fernández es licenciado en comunicaciones y periodista de la Universidad de Santiago de Chile (2018). Además, con diplomados en Community Manager del Instituto Profesional Arcos (2019) y de Educación, Memoria y Derechos Humanos de la Universidad de Chile (2020).

Paula Altamirano Ortiz es licenciada en Comunicación Social y periodista de la Universidad de Santiago de Chile (2018). Actualmente es estudiante del diplomado en Teorías de Género, Desarrollo y Políticas Públicas de la FACSO de la Universidad de Chile.

\section{- ¿Cómo citar?}

Lizana, C. \& Altamirano, P. (2021). Revalorización cultural selk'nam: visiones desde la producción de obras artístico-culturales basadas en la etnia. Comunicación y Medios, (43), 127-138. https://doi.org/10.5354/0719-1529.2021.58763 